\title{
Phase 1 trials of PEGylated recombinant human hyaluronidase PH20 in patients with advanced solid tumours
}

\section{This article has been corrected since Advance Online Publication and a corrigendum is also printed in this issue}

Jeffrey R Infante ${ }^{\star}$, , Ronald L Korn ${ }^{2}$, Lee S Rosen ${ }^{3}$, Patricia LoRusso ${ }^{4}$, Samuel S Dychter ${ }^{5}$, Joy Zhu ${ }^{6}$, Daniel C Maneval ${ }^{7}$, Ping Jiang ${ }^{7}, \mathrm{H}$ Michael Shepard ${ }^{7}$, Gregory Frost ${ }^{8}$, Daniel D Von Hoff ${ }^{9}$, Mitesh J Borad ${ }^{10}$ and Ramesh K Ramanathan ${ }^{10}$

\begin{abstract}
${ }^{1}$ Early Development Oncology, Janssen Research \& Development, LLC, Welsh \& McKean Roads, Spring House, PA 19477, USA; ${ }^{2}$ Scottsdale Medical Imaging, 9700 N. 91st Suite C-200, Scottsdale, AZ 85258, USA; ${ }^{3}$ Division of Hematology-Oncology, University of California - Los Angeles, 2020 Santa Monica Boulevard, Suite 600, Santa Monica, CA 90404, USA; ${ }^{4}$ Yale Cancer Center, PO Box 208028, New Haven, CT 06520, USA; ${ }^{5}$ Fate Therapeutics, Inc., 3535 General Atomics Court, San Diego, CA 92121, USA; ${ }^{6}$ SBIO Pte, Ltd., 1 Science Park Road, \#05-09, The Capricorn Science Park 2, Singapore, 117 528, Singapore; ${ }^{7}$ Halozyme Therapeutics, Inc., 11388 Sorrento Valley Road, San Diego, CA 92121, USA; ${ }^{8}$ F1 Bioventures LLC, 505 S. Flagler Drive, West Palm Beach, FL 33401, USA; ${ }^{9}$ Translational Genomics Research Institute (TGen), 445 N. Fifth Street, Phoenix, AZ 85004, USA and ${ }^{10}$ Mayo Clinic, 13400 E. Shea Boulevard, Scottsdale, AZ 85259, USA
\end{abstract}

Background: Hyaluronan accumulation in tumour stroma is associated with reduced survival in preclinical cancer models. PEGPH2O degrades hyaluronan to facilitate tumour access for cancer therapies. Our objective was to assess safety and antitumour activity of PEGPH2O in patients with advanced solid tumours.

Methods: In HALO-109-101 ( $N=14)$, PEGPH20 was administered intravenously once or twice weekly $\left(0.5\right.$ or $\left.50 \mu \mathrm{gg}^{-1}\right)$ or once every 3 weeks $\left(0.5-1.5 \mu \mathrm{g} \mathrm{kg}^{-1}\right)$. In HALO-109-102 $(\mathrm{N}=27)$, PEGPH20 was administered once or twice weekly $\left(0.5-5.0 \mu \mathrm{gg}^{-1}\right)$, with dexamethasone predose and postdose.

Results: Dose-limiting toxicities included grade $\geqslant 3$ myalgia, arthralgia, and muscle spasms; the maximum tolerated dose was $3.0 \mu \mathrm{gg}^{-1}$ twice weekly. Plasma hyaluronan increased in a dose-dependent manner, achieving steady state by Day 8 in multidose studies. A decrease in tumour hyaluronan level was observed in 5 of the 6 patients with pretreatment and posttreatment tumour biopsies. Exploratory imaging showed changes in tumour perfusion and decreased tumour metabolic activity, consistent with observations in animal models.

Conclusions: The tumour stroma has emerging importance in the development of cancer therapeutics. PEGPH20 $3.0 \mu \mathrm{gg}^{-1}$ administered twice weekly is feasible in patients with advanced cancers; exploratory analyses indicate antitumour activity supporting further evaluation of PEGPH2O in solid tumours.

Hyaluronan (HA) is a large, linear, glycosaminoglycan comprising repeating disaccharides of glucuronic acid and $\mathrm{N}$-acetylglucosamine (Toole and Slomiany, 2008). In many normal vertebrate tissues, HA has an important structural role in the extracellular matrix (ECM). HA also accumulates in conditions involving rapid and invasive cell division, including foetal development (Knudson 
and Toole, 1998) and cancer (Toole and Slomiany, 2008). The hygroscopic nature and net negative charge of $\mathrm{HA}$ result in an accumulation of water in the tumour microenvironment (TME); HA may absorb approximately 15 water molecules per disaccharide, leading to ECM swelling, increased tumour interstitial fluid pressure, and collapse of the tumour vasculature (Shepard, 2015).

HA accumulates in the ECM of many solid tumours, including pancreatic ductal adenocarcinoma (PDA), breast cancer, and prostate cancer (Jacobetz et al, 2013). Tumours accumulating HA (termed 'HA-High') are more aggressive in preclinical models (Jiang et al, 2012; Provenzano et al, 2012; Jacobetz et al, 2013; Kultti et al, 2014). Notably, elevated HA in the TME has been associated with induction of epithelial-to-mesenchymal transition (Rilla et al, 2012) and development of highly malignant, migratory/ invasive phenotypes in both normal and transformed epithelial cells (Bertrand et al, 1992; Pilarski et al, 1994; Abetamann et al, 1996; Zoltan-Jones et al, 2003). These associations also have been observed where HA accumulation is a predictor of shorter survival in patients with various tumour types (Ropponen et al, 1998; Setala et al, 1999; Auvinen et al, 2000; Whatcott et al, 2015).

Hyaluronidases are naturally occurring enzymes that depolymerise HA. Injectable animal-derived hyaluronidases have a 60year history of clinical use; there is evidence that these hyaluronidases (administered intravenously ((IV)) may improve the clinical activity of chemotherapy (Baumgartner et al, 1998; Pillwein et al, 1998). However, poor pharmaceutical characteristics (e.g., short half-life $\left(t_{1 / 2}\right)$, immune response to animal-derived product) have limited clinical investigation. The PEGylated form of recombinant human hyaluronidase $\mathrm{PH} 20$ (PEGPH20) is engineered to reduce systemic clearance and thus prolong circulatory time (Thompson et al, 2010). In an HA-High prostate cancer xenograft model, a single dose of PEGPH20 removed HA from the TME, leading to a significant reduction in tumour interstitial fluid pressure and increase in microvessel luminal area (Thompson et al, 2010). Using a repeat dose schedule in this model, tumour growth was inhibited by $70 \%$. Direct antitumour effects of PEGPH20 may be a result of release of sequestered growth factors and cytokines, increased cell-cell contact, and decreased nuclear hypoxia-related proteins associated with HA reduction (Jiang et al, 2012; Kultti et al, 2014).

In the LSL-Kras ${ }^{G 12 D /+} ; L S L-T r p 53^{R 172 H /+} ; P d x-1-C r e$ (KPC) mouse model of PDA, Jacobetz et al (2013) reported rapid removal of tumour HA following IV PEGPH20 that was associated with increased tumour vessel patency and increased intratumoural delivery of doxorubicin and gemcitabine. Combined treatment with PEGPH20 and gemcitabine significantly decreased tumour growth $(P<0.001)$ and prolonged survival $(P=0.002)$ compared with gemcitabine alone (Jacobetz et al, 2013). Using the same KPC mouse model, Provenzano et al (2012) similarly demonstrated that the addition of PEGPH20 to gemcitabine significantly decreased tumour proliferation $(P=0.0009)$ and the incidence of metastases (93\% of animals treated with gemcitabine alone vs $43 \%$ treated with gemcitabine plus PEGPH20).

We report the safety, pharmacokinetics (PK), pharmacodynamics (PD), and preliminary antitumour activity of single-agent PEGPH20 in two, first-in-human, phase 1 studies in patients with advanced solid tumours refractory to standard therapies.

\section{MATERIALS AND METHODS}

Study design. HALO-109-101 (NCT00834704; referred to herein as Study 101) was a dose-escalation study of single-agent PEGPH20 initiated in 2009. HALO-109-102 (NCT01170897; referred to herein as Study 102) followed in 2010 to evaluate PEGPH20 with the addition of dexamethasone to address musculoskeletal events (MSEs) observed in Study 101. The primary objective for both studies was to determine the PEGPH20 dose for future phase 1 combination trials based on the safety profile observed over a range of doses. Secondary objectives were to describe the PK profile of PEGPH20 and explore PD and efficacy end points that may further guide clinical use. Both studies were conducted in accordance with good clinical practice and the ethical principles founded in the Declaration of Helsinki and were authorised by the institutional review boards at each clinical site. Patients provided signed informed consent forms before study participation.

In both studies, eligible patients were at least 18 years of age with a diagnosis of pathologically confirmed, measurable, metastatic or locally advanced solid tumours (Therasse et al, 2000) and refractory to standard treatment. Additional requirements included Karnofsky performance status $\geqslant 70 \%$; ejection fraction $\geqslant 50 \%$; absolute neutrophil count $\geqslant 1.5 \times 10^{9} 1^{-1}$; platelets $\geqslant 100 \times 10^{9}$ $1^{-1}$; hemoglobin $\geqslant 9.0 \mathrm{~g} \mathrm{dl}^{-1}$ without transfusions; bilirubin $<1.3 \times$ the upper limit of normal (ULN); liver function tests $\leqslant 5 \times$ ULN with liver metastases or $\leqslant 2.5 \times$ ULN without liver metastases; serum creatinine within normal limits (WNL) or calculated creatinine clearance $\geqslant 60 \mathrm{ml} \mathrm{min}^{-1} 1.73 \mathrm{~m}^{-2}$ if creatinine $>$ WNL; prothrombin time/international normalised ratio WNL or international normalised ratio $2-3$ on warfarin; partial thromboplastin time WNL or $1.2 \times$ ULN if on warfarin; life expectancy $\geqslant 3$ months; and recovery (National Cancer Institute Common Terminology Criteria for Adverse Events (NCI-CTCAE) $\leqslant$ grade 1) from toxic or other effects of previous therapy, including radiation, chemotherapy, and surgery. Patients were excluded if they had any of the following conditions: active uncontrolled bacterial, viral, or fungal infection requiring systemic therapy; known infection with human immunodeficiency virus or hepatitis B or C; heparin treatment; known allergy to hyaluronidase; and brain metastases (although Study 101 permitted inclusion of patients with brain metastases that were adequately controlled with stable signs and symptoms with no corticosteroids for $\geqslant 3$ months).

Study treatments. In Study 101, the starting dose of PEGPH20 was $50 \mu \mathrm{g} \mathrm{kg}^{-1}$ administered IV twice weekly (BIW) for 3 weeks of each 4 -week cycle. This dose (1/10th the lowest $\mathrm{mg} \mathrm{kg}^{-1}$ dose tested in the rat) was selected based on animal studies using doses up to $10.5 \mathrm{mg} \mathrm{kg}^{-1}$ (cynomolgus monkey) and $25 \mathrm{mg} \mathrm{kg}^{-1}$ (rat). At these doses, reversible decreases in joint range of motion (without associated histological changes) were observed but were not considered to adversely affect daily activity (Veneziale et al, 2015). Because of the development of grade 4 arthralgia, myalgia, and muscular weakness and grade 3 musculoskeletal pain after the first $50-\mu \mathrm{g} \mathrm{kg}^{-1}$ dose, the protocol was amended so that the starting dose was changed to $0.5 \mu \mathrm{g} \mathrm{kg}^{-1}$ BIW. The first patient enrolled at $0.5 \mu \mathrm{g} \mathrm{kg}^{-1}$ BIW experienced grade 3 myalgia and muscle spasm 1 day after the second dose (Day 5), and the schedule was then adjusted to every 21 days (Q21D). Other doses tested using the Q21D schedule included 0.75, 1.0, and $1.5 \mu \mathrm{g} \mathrm{kg}^{-1}$.

Parallel preclinical studies identified beagles as a candidate animal model for testing sensitivity to PEGPH20, as described for some xenobiotics (Hayes et al, 1989; Abbott et al, 2004). Dosing beagles with PEGPH20 resulted in dose-dependent muscle stiffness, but no systemic inflammatory markers were found. Dexamethasone treatment limited muscle-specific effects in the dog model without reducing antitumour activity in a mouse xenograft model (Shepard et al, 2010). Study 102 was then initiated, incorporating dexamethasone and enabling a more frequent PEGPH20 dosing schedule. Study 101 was closed to enrollment.

In Study 102, PEGPH20 was administered at 4 dose levels (0.5, 1.6, 3.0, and $5.0 \mu \mathrm{g} \mathrm{kg}^{-1}$ ) by slow IV push (over $5 \mathrm{~min}$ ) once 
weekly or BIW during the first 4-week cycle, then once weekly for subsequent cycles. A BIW schedule during Cycle 1 permitted an increased dose intensity to theoretically maximise HA degradation in the tumour followed by a weekly schedule to maintain the effects on TME. Based on preclinical studies, dexamethasone (up to $8 \mathrm{mg}$ twice daily) was administered orally $1 \mathrm{~h}$ before and $8-12 \mathrm{~h}$ after each PEGPH20 infusion. Dexamethasone tapering was allowed in Cycle 3 to assess the need for continuation and to avoid associated side effects. Administration of nonsteroidal anti-inflammatory drugs and/or cyclobenzaprine was also allowed to manage MSEs.

\section{End points and assessments}

Safety. Patients were monitored for adverse events (AEs) throughout each study and until 28 days after the last PEGPH20 dose. Clinically significant decrements in clinical status, electrocardiogram and echocardiogram data, and physical examination findings were considered AEs. Laboratory data were collected and physical examinations were conducted at each visit. AEs and changes in laboratory data were graded according to the NCI-CTCAE (US Department of Health and Human Services, 2009).

During Cycle 1 (21 days for Study 101; 28 days for Study 102), patients were assessed for dose-limiting toxicities (DLTs), defined as any $\geqslant$ grade 3 toxicity (except nausea and vomiting in the absence of effective antiemetic therapy (both studies) and grade 3 MSEs that were readily treated and resolved to $\leqslant$ grade 2 within $24 \mathrm{~h}$ (Study 102 only)) or any persistent grade 2 toxicity that remained unresolved after 21 days or that otherwise limited study compliance. The maximum tolerated dose (MTD) was determined as the highest dose at which no more than 1 of the 6 evaluable patients experienced a DLT.

Pharmacokinetics. In both studies, blood samples were collected in Cycle 1 on Day 1 immediately before PEGPH20 and at 15, 30, and $45 \mathrm{~min}$ and 1,2,4, and $8 \mathrm{~h}$ after the start of infusion; on Day 2 between 24 and $32 \mathrm{~h}$ after the Day 1 dose; on Day 3 between 48 and $56 \mathrm{~h}$ after the Day 1 dose; on Days 8 and 15; and before the Day 1 dosing of each subsequent cycle. In Study 102, additional Cycle 1 samples were collected before dosing on Days 4, 11, 15, 18, 22, and 25 , and $1 \mathrm{~h}$ postinfusion on Days 8,15 , and 22. Samples were also obtained before dosing on Day 15 of each subsequent cycle.

PEGPH20 concentrations were determined by measuring hyaluronidase activity using a validated biotinylated-HA chromogenic assay (Frost and Stern, 1997). PEGPH20 concentrations were expressed as units of hyaluronidase activity $\left(\mathrm{U} \mathrm{ml}^{-1}\right)$, as interpolated from a calibration curve with sensitivity of $0.3125 \mathrm{U} \mathrm{ml}^{-1}$. PK parameters were estimated from plasma concentration-time data using standard noncompartmental methods and included maximal concentration $\left(C_{\max }\right)$ and median time to maximal concentration $\left(T_{\max }\right)$. The area under the concentration-time curve from time 0 to $72 \mathrm{~h}\left(\mathrm{AUC}_{0-72 \mathrm{~h}}\right)$ was calculated by using conventional linear trapezoidal summation. The elimination rate constant $\left(k_{\mathrm{e}}\right)$ was estimated using leastsquares regression analysis of the terminal log-linear portion of the serum concentration-time profile. The $t_{1 / 2}$ was calculated by dividing $\ln (2)$ (i.e., the natural logarithm of 2) by $k_{\mathrm{e}}$.

\section{Pharmacodynamics}

HA plasma concentrations. The in vivo pharmacologic activity of PEGPH20 was evaluated by measuring plasma concentrations of HA following PEGPH20 administration. Blood samples were collected and analysed at a bioanalytical laboratory (MicroConstants, Inc., San Diego, CA, USA) using a validated assay (Printz et al, 2017). Plasma samples were enzymatically digested with chondroitinase $\mathrm{ABC}$ to hydrolyse different sizes of $\mathrm{HA}$ to the smallest HA-disaccharide, followed by derivatization with 4nitrobenzyl hydroxylamine and analysis using high-performance liquid chromatography and tandem mass spectrometry. Plasma concentrations of HA were determined using reference standards and reported as nanograms of HA-disaccharide per millilitre of plasma. The lower limit of quantification was $42.3 \mathrm{ng} \mathrm{ml}^{-1}$ (normal range, $10-100 \mathrm{ng} \mathrm{ml}^{-1}$ ) (Fraser et al, 1997).

Histochemical detection of $\mathrm{HA}$ in tumour tissue. When clinically feasible, tumour tissue was collected pretreatment and posttreatment; HA staining was performed and analysed with a prototype assay using biotinylated-HA-binding protein $\left(2.5 \mu \mathrm{g} \mathrm{ml}^{-1}\right.$; Seikagaku Corporation, Tokyo, Japan) as a probe, followed by streptavidin-horseradish peroxidase and a colorimetric detection system, as previously described (Auvinen et al, 2000; Thompson et al, 2010).

Imaging. Imaging modalities were conducted in 20 patients enrolled in Study 102 to explore the underlying biological behavior of tumours following exposure to PEGPH20. In a prospectively planned analysis, dynamic contrast-enhanced magnetic resonance imaging (DCE-MRI) was used before and after treatment to evaluate tumour perfusion. In addition, positron emission tomography with $\left[{ }^{18} \mathrm{~F}\right] 2$-fluoro-2-deoxyglucose positron emission tomography/computed tomography $\left({ }^{18} \mathrm{~F}\right.$-FDG-PET/CT) was performed to assess tumour metabolic activity. The standardised uptake value (SUV) measures ${ }^{\text {I8 }}$ F-FDG activity; the highest SUVs for target lesions (no more than two per organ and five total) were summed and served as a measure of target lesion tumour burden. The DCE-MRI and ${ }^{18}$ F-FDG-PET/CT scans were performed at screening, 1-3 days following the first dose, and at the end of Cycle 1 (i.e., 1-3 days after the last dose). An analysis of imaging studies was performed by a central radiology lab (Imaging Endpoints, Scottsdale, AZ, USA). Change in tumour burden was also centrally evaluated by measuring the sum of the longest diameter for target and nontarget lesions by CT scan at baseline and on Day 22 of every other cycle, beginning with Cycle 2.

Efficacy analyses. These studies were not powered for formal efficacy analyses. In Study 101, objective response was assessed per Response Evaluation Criteria in Solid Tumour (RECIST) v.1.0 (Therasse et al, 2000). In Study 102, efficacy was assessed through radiological imaging of target and nontarget lesions per RECIST v.1.0. Scans were performed at baseline and Day 22 of every other cycle (beginning with Cycle 2). End points included objective response rate, duration of response, and change in tumour burden.

Statistical analysis. The safety population included patients who received at least one dose of PEGPH20. The DLT-evaluable population was defined as patients who completed Cycle 1 of study treatment and associated assessments for safety and efficacy or experienced a DLT in the first cycle. In Study 102, patients must have completed at least $75 \%$ of Cycle 1 without missing doses because of study drug-related toxicities and must have received the first dose of study drug prior to MTD determination. No formal statistical analyses were planned or performed in Study 102. Although Study 101 was designed to include statistical analysis, the small sample size precluded any formal testing. Safety, exploratory efficacy as determined by metabolic response (Allen-Auerbach and Weber, 2009), and PK/PD findings are summarised by dose group using descriptive statistics.

\section{RESULTS}

Patient characteristics and disposition. Fourteen patients were enrolled in Study 101: the first patient enrolled in March 2009 and the last patient completed the study in March 2011. Study 102 enrolled 27 patients: the first patient enrolled in July 2010 and the last patient completed the study in January 2013. Patient characteristics were similar in both studies (Table 1). The most 
Table 1. Demographic and baseline characteristics

\begin{tabular}{|c|c|c|}
\hline & $\begin{array}{c}\text { Study } 101 \\
(N=14)\end{array}$ & $\begin{array}{c}\text { Study } 102 \\
(N=27)\end{array}$ \\
\hline \multicolumn{3}{|l|}{ Age } \\
\hline Median age, years (range) & $62(55-86)$ & $62(31-78)$ \\
\hline \multicolumn{3}{|l|}{ Gender } \\
\hline Male, $n(\%)$ & $9(64)$ & $11(41)$ \\
\hline \multicolumn{3}{|l|}{ KPS, $n(\%)$} \\
\hline $\begin{array}{l}\leqslant 80 \% \\
\geqslant 90 \%\end{array}$ & $\begin{array}{l}6(43) \\
8(57)\end{array}$ & $\begin{array}{r}8(30) \\
19(70)\end{array}$ \\
\hline \multicolumn{3}{|c|}{ Primary tumour type, $n(\%)$} \\
\hline $\begin{array}{l}\text { Colorectal } \\
\text { Pancreatic } \\
\text { Cholangiocarcinoma } \\
\text { Pulmonary } \\
\text { Oesophageal } \\
\text { Prostate } \\
\text { Other }\end{array}$ & $\begin{array}{l}5(36) \\
2(14) \\
0 \\
1(7) \\
0 \\
3(21) \\
3(21)^{a}\end{array}$ & $\begin{array}{l}8(30) \\
5(19) \\
3(11) \\
3(11) \\
2(7) \\
0 \\
6(22)^{b}\end{array}$ \\
\hline \multicolumn{3}{|c|}{ Number of prior systemic therapies } \\
\hline Median (range) & $4.5(2-16)$ & $4(1-11)$ \\
\hline
\end{tabular}

common primary malignancies overall were colorectal $(n=13$ $(32 \%))$ and pancreatic $(n=7(17 \%))$. Patients were heavily pretreated, receiving a median of 4.5 (Study 101) and 4 (Study 102) prior lines of anticancer treatment (including biologics in up to half of the patients). All patients in both studies discontinued treatment, primarily due to disease progression (10 out of 14 patients, Study 101; 20 out of 27 patients, Study 102).

Safety. In Study 101, all 14 patients received at least 1 dose of PEGPH20: 6 (43\%) received 1 dose, 7 (50\%) received 2 doses, and 1 (7\%) received 3 doses. Median treatment duration was 13 days (range, 1-43 days). All patients were evaluable for DLTs (Table 2). Six events in the first 3 patients enrolled (the first 2 patients treated BIW at $50 \mu \mathrm{g} \mathrm{kg}^{-1}$ and the first patient treated BIW at $0.5 \mu \mathrm{g} \mathrm{kg}^{-1}$ ) met the criteria for DLTs (Table 2). As a result, a less-frequent dosing schedule (single dose in a Q21D cycle, with subsequent cycles initiated only on successful completion of Cycle 1 without disease progression or undue toxicity) and lower doses compared with the starting dose $\left(0.5,0.75,1.0\right.$, and $\left.1.5 \mu \mathrm{g} \mathrm{kg}^{-1}\right)$ were used for subsequent dose groups. No DLTs were observed in any of the patients who received PEGPH20 on a Q21D schedule. No MTD was identified in Study 101.

In Study 102, 26 out of 27 enrolled patients received at least 1 dose of PEGPH20 administered once weekly or BIW during the first 28-day cycle and weekly in subsequent cycles, with dexamethasone premedication. Of the 26 patients dosed with PEGPH20, 11 (42\%) received 1 cycle, 12 (46\%) received 2 cycles, and $3(12 \%)$ received 3 cycles of PEGPH20. Median number of PEGPH20 doses was 8 (range, 1-28), and median treatment duration was 29 days (range, 1-164 days). Eighteen patients in six dose-escalation cohorts were evaluable for DLTs (Table 2). Six DLTs (all musculoskeletal and connective tissue disorders) were reported in three patients and led to discontinuation in all cases (Table 2). All DLTs were considered treatment related; all DLTs except 1 (grade 2 muscle spasms in 1 patient) resolved without sequelae. One patient was evaluable at each $5.0-\mu \mathrm{g} \mathrm{kg}^{-1}$ dosing schedule and experienced DLTs in each case (Table 2). As a result, this dose level was not explored further and the MTD (with dexamethasone pre- and post-PEGPH20 dosing) was defined as $3.0 \mu \mathrm{g} \mathrm{kg}^{-1}$ at both dosing frequencies.
Table 2. Dose-limiting toxicities by study and dose level

\begin{tabular}{|c|c|c|}
\hline $\begin{array}{l}\text { PEGPH20 dose and } \\
\text { schedule }\end{array}$ & $\begin{array}{l}\text { Evaluable } \\
\text { patients, } n\end{array}$ & Dose-limiting toxicity \\
\hline \multicolumn{3}{|l|}{ Study $101(N=14)$} \\
\hline $\begin{array}{l}50 \mu \mathrm{kg}^{-1} \text { BIW } \\
\\
0.5 \mu \mathrm{g} \mathrm{kg}^{-1} \mathrm{BIW} \\
0.5 \mu \mathrm{g} \mathrm{kg}^{-1} \mathrm{Q} 21 \mathrm{D} \\
0.75 \mu \mathrm{kg}^{-1} \mathrm{Q} 21 \mathrm{D} \\
1.0 \mu \mathrm{kg}^{-1} \mathrm{Q} 21 \mathrm{D} \\
1.5 \mu \mathrm{kg}^{-1} \mathrm{Q} 21 \mathrm{D}\end{array}$ & $\begin{array}{l}1 \\
3 \\
4 \\
3 \\
1\end{array}$ & $\begin{array}{l}\text { Grade } 4 \text { arthralgia; myalgia; } \\
\text { muscle weakness ( } 1 \text { patient) } \\
\text { Grade } 3 \text { musculoskeletal pain } \\
\text { (1 patient) } \\
\text { Grade } 3 \text { myalgia and muscle } \\
\text { spasms }\end{array}$ \\
\hline \multicolumn{3}{|l|}{ Study $102(N=27)^{b}$} \\
\hline $\begin{array}{l}\text { BIW dosing } \\
0.5 \mu \mathrm{kg}^{-1} \text { BIW } \\
1.6 \mu \mathrm{gg}^{-1} \text { BIW } \\
3.0 \mu \mathrm{kg}^{-1} \text { BIW } \\
5.0 \mu \mathrm{gg}^{-1} \text { BIW }\end{array}$ & $\begin{array}{l}1 \\
3 \\
6 \\
1\end{array}$ & $\begin{array}{l}\text { Grade } 3 \text { myalgia; grade } 2 \\
\text { muscle spasms, leg }\end{array}$ \\
\hline $\begin{array}{l}\text { Weekly dosing } \\
3.0 \mu \mathrm{g} \mathrm{kg}^{-1} \text { weekly } \\
5.0 \mu \mathrm{g} \mathrm{kg}^{-1} \text { weekly }\end{array}$ & $\begin{array}{l}6 \\
1\end{array}$ & $\begin{array}{l}\text { Grade } 3 \text { muscle spasms, } \\
\text { hands and leg ( } 1 \text { patient) } \\
\text { Grade } 3 \text { muscle spasms, leg; } \\
\text { grade } 3 \text { muscle spasms, hand }\end{array}$ \\
\hline $\begin{array}{l}\text { Abbreviations: BIW = twice } \mathrm{n} \\
\text { a Two patients received a sin } \\
\text { after } 2 \text { patients were dosed } \\
\mathbf{b}_{\text {Eighteen patients were eval }} \\
\text { was announced and were ex }\end{array}$ & $\begin{array}{l}\text { 221D, every } 21 \mathrm{~d} \\
\text { ninistration at this } \\
\text { evel. } \\
\text { or DLTs. Five patic } \\
\text { from the DLT-eva }\end{array}$ & $\begin{array}{l}\text { level. Dose was decreased } 100 \text {-fold } \\
\text { nts initiated treatment after the MTD } \\
\text { luable population. }\end{array}$ \\
\hline
\end{tabular}

All patients experienced at least $1 \mathrm{AE}$, and most AEs were grade 1 or 2 (Table 3). Most common treatment-emergent AEs (all grades) across both studies were of musculoskeletal origin (muscle spasms (58\%), myalgia (40\%)), followed by fatigue (38\%). Most common grade $\geqslant 3$ AEs were myalgia (10\%), dyspnoea (10\%), and muscle spasms (8\%). The incidence and severity of treatmentrelated MSEs (arthralgia, myalgia, muscle weakness, and musculoskeletal pain) may be dependent on PEGPH20 dose, with the highest incidence of grade 3/4 MSEs in patients receiving $50 \mu \mathrm{g} \mathrm{kg}^{-1}$ (2 patients) in Study 101 and in 2 patients receiving $5.0 \mu \mathrm{g} \mathrm{kg}^{-1}$ PEGPH20 in Study 102 (Table 2). In support of this relationship, circulating HA concentrations were most elevated in patients receiving higher doses of PEGPH20 (Figure 1B). However, no causal link has been made between serious AEs (SAEs) and HA plasma concentrations.

In Study 101, 11 SAEs were reported in 5 patients. Five SAEs observed in the first three patients enrolled were considered to be related to study treatment and were dose limiting, as described. The first patient developed grade 4 arthralgia, myalgia, and muscle weakness on Day 1 following a single $50-\mu \mathrm{g} \mathrm{kg}^{-1}$ PEGPH20 dose; study drug was discontinued, with resolution of arthralgia and myalgia by Day 16 . The second patient, also treated with a single $50-\mu \mathrm{g} \mathrm{kg}^{-1}$ PEGPH20 dose, experienced grade 3 musculoskeletal pain on Day 2; PEGPH20 was discontinued and pain managed with analgesics and dexamethasone, resolving on Day 5. The third patient (receiving $0.5 \mu \mathrm{g} \mathrm{kg}^{-1}$ PEGPH20) experienced grade 3 myalgia and muscle spasms beginning on Day 5 and following the second $0.5-\mu \mathrm{g} \mathrm{kg}^{-1}$ BIW dose of PEGPH20. Study 101 was discontinued at this point until the sponsor determined an appropriate management strategy for MSEs. Myalgia was managed with nonsteroidal anti-inflammatory drugs; muscle spasms were managed with muscle relaxants. In Study 102, 21 SAEs were reported in 12 patients; none were MSEs and none were attributed to PEGPH20.

Six patients died during the 2 studies (1 in Study 101; 5 in Study 102); 4 deaths were related to disease progression. In Study 101, an 
Table 3. Most common treatment-emergent adverse events, safety population ( $\geqslant 10 \%$ of patients)

\begin{tabular}{|c|c|c|c|c|c|}
\hline \multirow[b]{2}{*}{$\begin{array}{l}\text { Adverse } \\
\text { event, n (\%) }\end{array}$} & \multicolumn{2}{|c|}{ Study101 $(n=14)$} & \multicolumn{2}{|c|}{ Study $102(n=26)$} & \multirow{2}{*}{$\begin{array}{c}\begin{array}{c}\text { Overall } \\
(N=40)\end{array} \\
\text { All } \\
\text { grades }\end{array}$} \\
\hline & $\begin{array}{c}\text { Grade } \\
1 / 2\end{array}$ & $\begin{array}{c}\text { Grade } \\
3 / 4\end{array}$ & $\begin{array}{c}\text { Grade } \\
1 / 2\end{array}$ & $\begin{array}{c}\text { Grade } \\
3 / 4\end{array}$ & \\
\hline Muscle spasms & $5(36)$ & $1(7)$ & $15(58)$ & $2(8)$ & $23(58)$ \\
\hline Myalgia & $4(29)$ & $3(21)$ & $8(31)$ & $1(4)$ & $16(40)$ \\
\hline Fatigue & $6(43)$ & $1(7)$ & $7(27)$ & $1(4)$ & $15(38)$ \\
\hline Arthralgia & $2(14)$ & $1(7)$ & $11(42)$ & 0 & $14(35)$ \\
\hline $\begin{array}{l}\text { Peripheral } \\
\text { oedema }\end{array}$ & $1(7)$ & 0 & $12(46)$ & $1(4)$ & $14(35)$ \\
\hline Vomiting & $4(29)$ & $1(7)$ & $6(23)$ & 0 & $11(28)$ \\
\hline Abdominal pain & $1(7)$ & 0 & $8(31)$ & 0 & $9(23)$ \\
\hline $\begin{array}{l}\text { Musculoskeletal } \\
\text { pain }\end{array}$ & 0 & $1(7)$ & $6(23)$ & $1(4)$ & $8(20)$ \\
\hline Diarrhoea & $2(14)$ & 0 & $6(23)$ & 0 & $8(20)$ \\
\hline Nausea & $1(7)$ & $1(7)$ & $6(23)$ & 0 & $8(20)$ \\
\hline $\begin{array}{l}\text { Decreased } \\
\text { appetite }\end{array}$ & $2(14)$ & 0 & $6(23)$ & 0 & $8(20)$ \\
\hline Dyspnoea & $1(7)$ & $1(7)$ & $3(12)$ & $3(12)$ & $8(20)$ \\
\hline Constipation & $3(21)$ & 0 & $4(15)$ & 0 & $7(18)$ \\
\hline Dysphonia & 0 & 0 & $6(23)$ & 0 & $6(15)$ \\
\hline Asthenia & $2(14)$ & $1(7)$ & $1(4)$ & $1(4)$ & $5(13)$ \\
\hline $\begin{array}{l}\text { Abdominal } \\
\text { distention }\end{array}$ & $1(7)$ & 0 & $3(12)$ & $1(4)$ & $5(13)$ \\
\hline Anaemia & $1(7)$ & $1(7)$ & $2(8)$ & 0 & $4(10)$ \\
\hline Cellulitis & 0 & 0 & $2(8)$ & $2(8)$ & $4(10)$ \\
\hline
\end{tabular}

86-year-old male with malignant fibrous histiocytoma (right hip) and pulmonary metastases and a history of congestive heart failure and hypertension received a single $50-\mu \mathrm{g} \mathrm{kg}^{-1}$ dose of PEGPH20 (as mentioned, study treatment was stopped owing to grade 4 arthralgia, myalgia, and muscle weakness). On Day 20, the patient developed pulmonary oedema and died; on autopsy, this SAE was considered to be related to underlying congestive heart failure and ischaemic heart disease. In Study 102, a 65-year-old female with metastatic non-small cell lung cancer (NSCLC) and a history of chronic obstructive pulmonary disease and hypertension received 3 BIW doses of $5.0 \mu \mathrm{g} \mathrm{kg}^{-1}$ PEGPH20 in Cycle 1. Study treatment was discontinued at that time owing to grade 3 generalised myalgia. The patient was hospitalised for respiratory distress 17 days following the last dose and died 4 days later. Respiratory distress was considered by the investigator to be unrelated to PEGPH20; NSCLC was considered a contributing factor to the development of respiratory distress and the cause of death.

Pharmacokinetics. In Study 101, the PK profile of PEGPH20 was determined after the initial IV PEGPH20 dose. In the first 2 patients enrolled (PEGPH20 $50 \mu \mathrm{g} \mathrm{kg}^{-1}$ ), $C_{\max }$ averaged $30.9 \mathrm{U} \mathrm{ml}^{-1}$ and was reached soon after infusion; the $t_{1 / 2}$ averaged $31.8 \mathrm{~h}$ (Supplementary Table S1).

In most patients, plasma concentrations of PEGPH20 were measurable shortly after dosing but fell below the lower limit of quantification during the first day. As a result, detailed plasma concentration-time profiles of PEGPH20 could not be described and extrapolated PK parameters (e.g., clearance and $t_{1 / 2}$ ) were not individually estimated for these patients (Supplementary Table S1). Dose proportionality analyses for $\log C_{\max }$ and $\log \mathrm{AUC}_{0-72 \mathrm{~h}} v s \log$ dose suggested a dose-proportional increase in these parameters.
A
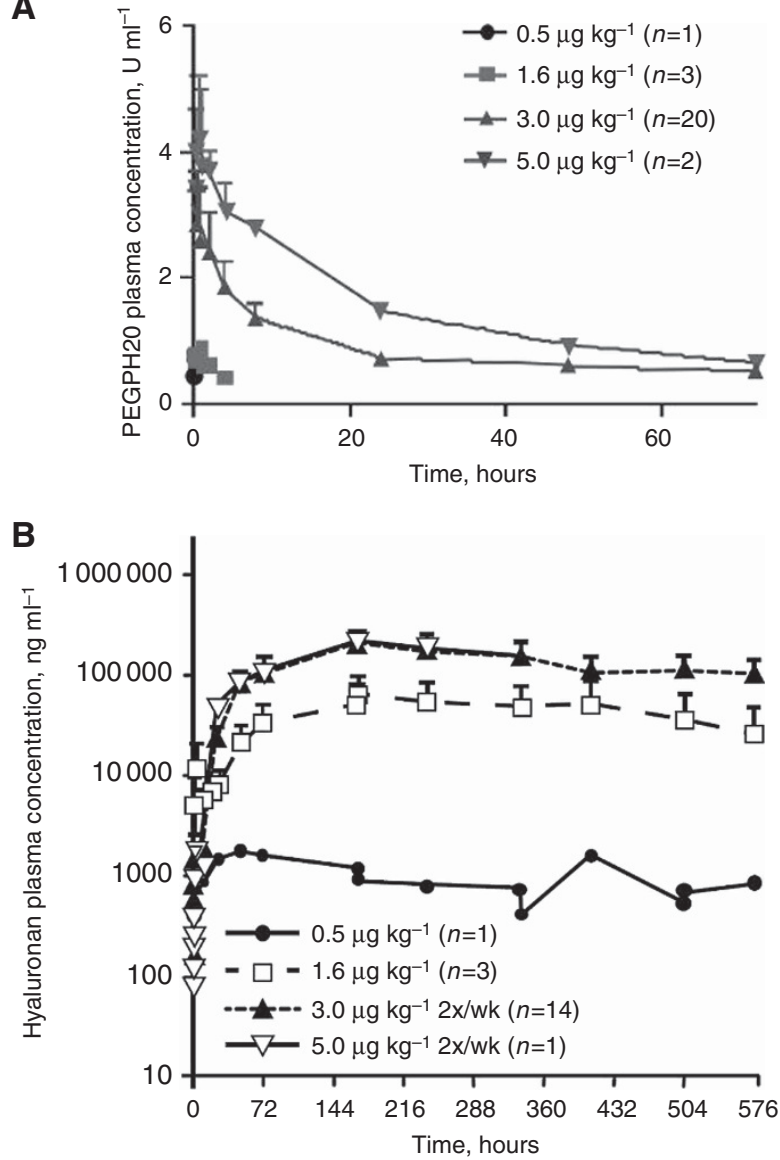

Figure 1. PEGPH2O Plasma Pharmacokinetics and Pharmacodynamics. Mean ( \pm s.e.m.) plasma concentration-time profiles for (A) PEGPH2O and (B) HA in Cycle 1. The majority of patients received PEGPH2O $3.0 \mu \mathrm{g} \mathrm{kg}^{-1}$ twice weekly.

Eight patients received multiple doses of PEGPH20; plasma concentrations were measurable after repeat administration in four patients. These plasma concentrations were low (range, 0.34 to $0.83 \mathrm{U} \mathrm{ml}^{-1}$ ), with no accumulation of PEGPH20 with repeated dosing.

Following the initial dose of PEGPH20 in Study 102, $T_{\max }$ ranged from 0.250 to $0.875 \mathrm{~h}$ (Table 4 ). Mean $C_{\max }$ ranged from $0.411 \mathrm{U} \mathrm{ml}^{-1}$ (0.5- $\mu \mathrm{g} \mathrm{kg}^{-1}$ dose) to $4.33 \mathrm{U} \mathrm{ml}^{-1}\left(5.0-\mu \mathrm{g} \mathrm{kg}^{-1}\right.$ dose). Increases in $C_{\max }$ were dose proportional. Mean ( \pm s.d.) $\mathrm{AUC}_{0-72 \mathrm{~h}}$ increased with dose, ranging from 5.61 $( \pm 1.25)$ U.h ml ${ }^{-1}\left(1.6-\mu \mathrm{g} \mathrm{kg}^{-1}\right.$ dose) to $106( \pm 4.48) \mathrm{U} \cdot \mathrm{h} \mathrm{ml}^{-1}$ (5.0- $\mu \mathrm{g} \mathrm{kg}^{-1}$ dose) (Figure $1 \mathrm{~A}$ and Table 4). Following repeated BIW dosing of PEGPH20, steady state was achieved by Day 8 with no accumulation of drug. No measurable PEGPH20 was detected in samples collected immediately before infusion. The plasma concentration-time profile of PEGPH20 appears to be well described by a linear, two-compartment model (Supplementary Figure S1).

Pharmacodynamics. In Study 102, the mean ( \pm s.e.m.) plasma $\mathrm{HA}$ concentration (expressed as $\mathrm{ng} \mathrm{ml}^{-1} \mathrm{HA}$ disaccharide) at baseline was $157( \pm 70) \mathrm{ng} \mathrm{ml}^{-1}$ in the 26 patients who were treated with PEGPH20. Dose- and time-dependent increases in plasma HA concentration were observed in patients who received $0.5-5.0 \mu \mathrm{g} \mathrm{kg}^{-1}$ PEGPH20 for 1 cycle (Figure 1A). HA concentrations reached steady state after 1 week of repeated dosing, and increased plasma HA concentrations were sustained throughout Cycle 1. Six patients had pretreatment and posttreatment tumour 
biopsies available for HA assessment. Posttreatment biopsies showed markedly lower HA levels for 5 of these patients, with the decrease in HA staining vs pretreatment biopsies ranging

Table 4. Pharmacokinetic parameters for PEGPH20 based on initial dose in study $102^{a}$

\begin{tabular}{|c|c|c|c|c|}
\hline & \multicolumn{4}{|c|}{ PEGPH20 dose, $\mu \mathrm{g} \mathrm{kg}^{-1}$} \\
\hline Parameter & $\begin{array}{c}0.5 \\
(n=1)\end{array}$ & $1.6(n=3)$ & $3.0(n=19)$ & $5.0(n=2)$ \\
\hline$T_{\max ,} h$ & 0.250 (NC) & $0.75(0.23-1.0)$ & $0.330(0.25-3.98)$ & $0.875(0.75-1.0)$ \\
\hline$C_{\max }, \mathrm{Uml}^{-1}$ & 0.411 (NC) & $0.901(0.154)$ & $2.06(0.917)$ & $4.330(1.31)$ \\
\hline $\begin{array}{l}\text { AUC }_{0-721} \\
\text { U.h ml }^{-1}\end{array}$ & NC & $5.61(1$ & $41.3(19.7)$ & $106(4.48)$ \\
\hline$t_{1 / 2}, h$ & NC & $4.99(3.03)$ & $16.4(12.0)$ & $27.0(12.1)$ \\
\hline \multicolumn{5}{|c|}{$\begin{array}{l}\text { Abbreviations: } A \cup C=\text { area under the curve; } N C=\text { not calculated. } \\
\text { a All parameters are reported as mean (s.d.) except } T_{\text {max }} \text { which is reported as median } \\
\text { (range). }\end{array}$} \\
\hline
\end{tabular}

between $34 \%$ and $80 \%$ (Figure $2 \mathrm{~A}$ ). For example, in a patient with cholangiocarcinoma, a $62 \%$ decrease in HA staining $v$ s baseline was observed 2 days following the eighth dose of $3.0 \mu \mathrm{g} \mathrm{kg}^{-1}$ PEGPH20 BIW. In the remaining patient, tumour HA was increased following PEGPH20 $3 \mu \mathrm{g} \mathrm{kg}^{-1}$; this phenomenon will need to be further examined in a large cohort study.

Exploratory imaging was performed per protocol for the first patient within each cohort in Study 102; additional patients were imaged per investigator and sponsor discretion. Overall, exploratory imaging data were available for 11 patients in Study 102: 11 patients had a baseline scan, 10 out of 11 had Day 1 scans, 11 had Day 2 scans, and 6 out of 11 had an end of Cycle 1 scan. Scans performed in the first 5 days of Cycle 1 demonstrated an early increase in median volume transfer constant between extravascular/extracellular space to plasma space $\left(K^{\text {trans }}\right)$ in 7 out of 12 (58\%) lesions on Day 1 and Day 2-5 scans in 6 patients (Patients $\mathrm{A}-\mathrm{E}$ and Patient $\mathrm{K}$ who had Day 2-5 scan only) (Figure $2 \mathrm{~B}$ ). In contrast, 1 lesion (Patient F) showed an elevated $K^{\text {trans }}$ on Day 1
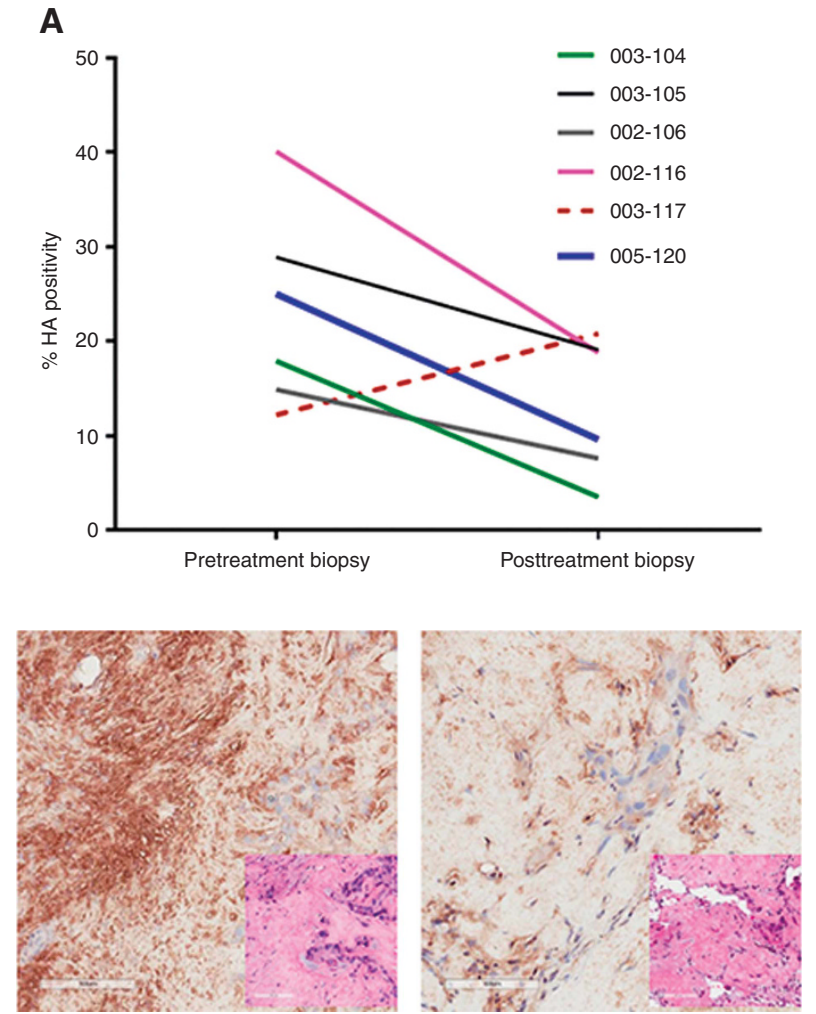
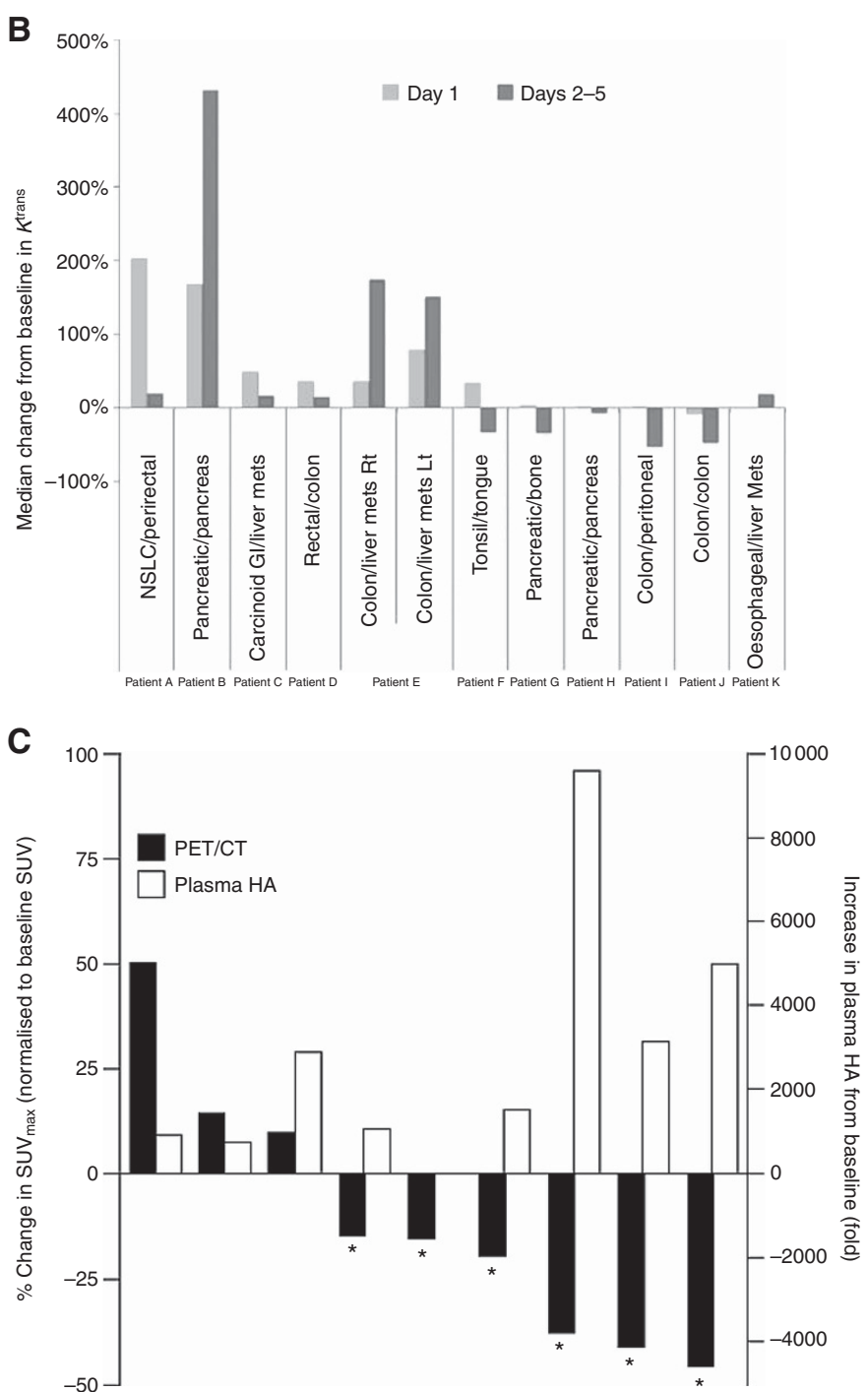

Figure 2. Effects of PEGPH2O on tumours. (A) HA levels in tumour tissue from baseline and post-PEGPH2O treatment $(n=6)$. Decreases in HA levels were observed in five patients. Representative micrographs of HA and H\&E (inset) staining demonstrated HA positivity at baseline (left) and 2 days after eight doses of PEGPH20 $3 \mu \mathrm{g} \mathrm{kg}^{-1}$ (right) from one patient (bold line). (B) Median change in tumour perfusion ( $K^{\text {trans }}$ ) by DCE-MRI following multiple doses of PEGPH2O $(n=11)$. (C) Change from baseline in plasma HA and tumour metabolic response (percentage of change in SUV $\left.V_{\text {max }}\right)$ at the end of Cycle $1(n=9)$; each set of bars represents a single patient. * Indicates patients with PMR by ${ }^{18} \mathrm{~F}-\mathrm{FDG}-\mathrm{PET} / \mathrm{CT}$ imaging during treatment $(n=6)$. Remaining patients had progressive $(n=2)$ or stable $(n=1)$ metabolic disease. 
but not on Days 2-5. Four lesions had no appreciable change in $K^{\text {trans }}$ on Day 1 or Days 2-5.

Changes in tumour metabolic activity were evaluated by measuring SUV by ${ }^{18} \mathrm{~F}-\mathrm{FDG}-\mathrm{PET} / \mathrm{CT}$. Of the patients for whom scans were performed, nine had baseline and end-of-Cycle 1 scans evaluable for assessment of metabolic response per European Organisation for Research and Treatment of Cancer (EORTC) criteria; partial metabolic response (PMR) was observed in 6 patients (67\%). Of those patients with PMR, 4 had peak postdose plasma HA concentrations $>1500$-fold greater than baseline (Figure 2C). In a patient with colorectal cancer and lung metastases, a reduction in tumour metabolic activity was apparent after 1 cycle of $3.0 \mu \mathrm{g} \mathrm{kg}^{-1}$ PEGPH20 BIW (Supplementary Figure S2).

Antitumour efficacy. None of the 14 patients treated with PEGPH20 in Study 101 demonstrated a complete or partial response, as expected based on the short duration of treatment exposure - all patients received $\leqslant 3$ doses of PEGPH20, with a median treatment duration of 13 days (range, 1-43 days). Two patients demonstrated stable disease at the time of the last efficacy assessment (1 patient each in the $0.5-\mu \mathrm{g} \mathrm{kg}^{-1}$ Q21D and $0.75-\mu \mathrm{g} \mathrm{kg}^{-1} \mathrm{Q} 21 \mathrm{D}$ groups).

Of the 25 evaluable patients in Study 102, no patients experienced RECIST-defined complete or partial response; 3 patients (12\%) had stable disease as their best response. Of these patients, 1 each had colon cancer, pancreatic adenocarcinoma, and cholangiocarcinoma at study entry. All 3 patients with stable disease were in the $3.0-\mu \mathrm{g} \mathrm{kg}^{-1}$ PEGPH20 dose group and were on the study for 4-6 cycles of treatment. Information on HA staining was available for 2 of these 3 patients; both had strong HA positivity in at least $25 \%$ of the tumour surface area (Supplementary Table S2).

As previously described, assessment of changes in tumour metabolic activity in Study 102 indicated PMR per EORTC criteria in 6 out of $9(67 \%)$ evaluable patients (Figure 2C). Patients achieving PMR had cholangiocarcinoma $(n=2)$, gall bladder cancer $(n=1)$, lung cancer $(n=1)$, colorectal cancer $(n=1)$, and adrenal cancer $(n=1)$. One of the patients with PMR also had stable disease by RECIST (Supplementary Table S2).

\section{DISCUSSION}

Study 101 was the first-in-human trial of PEGPH20. It was succeeded by Study 102, during which the MTD of PEGPH20 $\left(3.0 \mu \mathrm{g} \mathrm{kg}^{-1} \mathrm{BIW}\right)$ was determined. In both studies, the majority of AEs, and all DLTs, were musculoskeletal. Study 101 results informed the design of Study 102, during which patients received dexamethasone to manage MSEs. Although MSEs have no known etiology (i.e., histopathological changes, inflammation), they are assumed to be related to the degradation of HA. Others report that HA fragments may induce inflammation (McKee et al, 1996), although this is still disputed (Dong et al, 2016). Subsequent to our studies, a phase $1 \mathrm{~b}$ trial investigated the safety and efficacy of PEGPH20 plus gemcitabine in patients with PDA (NCT01453153) and reported similar rates of MSEs (muscle spasms, 54\%; myalgia, 43\%; arthralgia, 29\%) (Hingorani et al, 2016).

PK analyses indicate that PEGPH20 is cleared slowly from plasma with a $t_{1 / 2}$ of approximately 1 day in the $3.0-\mu \mathrm{g} \mathrm{kg}^{-1}$ group (MTD and recommended phase 2 dose from Study 102). Steadystate exposure of PEGPH20 increased with dose, without drug accumulation following multiple doses. PD assessments were consistent with PEGPH20's enzymatic degradation of HA. Plasma HA concentrations increased with increasing doses of PEGPH20 and were sustained during repeat dosing. Decreased tumour staining of HA was commensurate with elevated plasma HA concentrations, suggesting that a biologically active dose had been achieved.
In some patients, treatment with PEGPH20 led to decreased tumour uptake of ${ }^{18}$ F-FDG and increased $K^{\text {trans }}$ by DCE-MRI, consistent with preclinical studies demonstrating that PEGPH20 can increase tumour perfusion via vascular decompression, leading to an increase in tumour delivery of anticancer agents (Provenzano et al, 2012; Jacobetz et al, 2013). In preclinical models, PEGPH20 has also been reported to decrease nuclear hypoxia-related proteins and induced translocation of E-cadherin and $\beta$-catenin to the plasma membrane (Kultti et al, 2014). These findings are valuable in understanding the pharmacological activity of PEGPH20 in the TME in the absence of other agents. Further characterisation of the antitumour effects of PEGPH20 are ongoing.

Although no patients experienced a radiographic response by RECIST, an exploratory analysis of efficacy per EORTC criteria indicated that 6 out of 9 evaluable patients in Study 102 experienced a PMR as measured by functional imaging $\left({ }^{18} \mathrm{~F}-\mathrm{FDG}-\mathrm{PET} / \mathrm{CT}\right)$ at the end of Cycle 1 . These results support the biological activity and manageable safety profile of PEGPH20 alone and preclinical findings (Thompson et al, 2010; Provenzano et al, 2012; Jacobetz et al, 2013), but suggest that PEGPH20 may be more effective as part of a combination treatment approach.

Although small sample sizes in this study preclude formal analysis of clinical activity by tumour HA level, data from the phase $1 \mathrm{~b}$ trial in PDA suggest that the addition of PEGPH20 to gemcitabine may extend progression-free and overall survival, particularly in patients with HA-High tumours (Hingorani et al, 2016). Taken together, these findings support further investigation of PEGPH20 to target the TME in combination with other systemic anticancer agents.

In the phase $1 \mathrm{~b}$ study, a $29 \%$ thromboembolic event (TE) rate was reported in patients treated with PEGPH20 plus gemcitabine (Hingorani et al, 2016). In contrast, in Studies 101 and 102, only one grade $2 \mathrm{TE}$ was reported in a patient with PDA who received $3.0 \mu \mathrm{g} \mathrm{kg}^{-1}$ PEGPH20, and this event was considered unlikely to be related to study medication. This difference in TE rate may be related in part to our small sample size, the different types of malignancies included, and the use of PEGPH20 as monotherapy rather than in combination with chemotherapy. In this context, it is important to also consider the overall high rate of TE events in patients receiving chemotherapy for metastatic PDA (Maraveyas et al, 2012; Lyman et al, 2013). In the HALO-202 study of PEGPH20 plus gemcitabine and nab-paclitaxel in patients with untreated metastatic PDA (NCT01839487), patients received low molecular weight heparin for thromboprophylaxis during treatment to mitigate TE events.

In summary, PEGPH20 ( $3 \mu \mathrm{g} \mathrm{kg}^{-1}$ up to 2 times per week) administration is feasible in patients with advanced cancers. Exploratory analyses in a subset of patients demonstrating a reduction in tumour $\mathrm{HA}$ and associated improvement in tumour perfusion and decrease in tumour metabolic activity provide support for further evaluation of PEGPH20 in combination with anticancer therapies in patients with advanced solid tumours.

\section{ACKNOWLEDGEMENTS}

We thank the PEGPH20 team at Halozyme Therapeutics, Inc. for providing the experimental agent and recognise Marie Printz, Barry Sugarman, and Paneer Selvam for the development of plasma-based assays for analysis of PEGPH20 and HA. We also thank Dr David Z. D'Argenio for discussions and pharmacokinetic modeling expertise. Additionally, we thank Dr Patrick O'Connor and Dr Terrance Rugg for their assistance with drafting and reviewing regulatory documents related to these trials. Financial 
support for medical editorial assistance was provided by Halozyme Therapeutics, Inc. We thank William Sinkins, PhD, for his medical editorial assistance with this manuscript.

\section{CONFLICT OF INTEREST}

JRI reports that his institution has received research funding from Halozyme Therapeutics, Inc. RLK reports being a shareholder of Imaging Endpoints Core Lab. DDVH reports receiving a research grant to his institution from Halozyme Therapeutics, Inc. and is a consultant for Imaging Endpoints. LSR reports receiving a research grant to his institution from Halozyme Therapeutics, Inc. for the conduct of these clinical trials. PLR is currently on the DSMC for the pivotal phase 3 clinical trial of PEGPH20 in pancreatic cancer, sponsored by Halozyme Therapeutics, Inc., SSD is a shareholder of stock at Halozyme Therapeutics, Inc. and full-time employee at Fate Therapeutics. SSD, JZ, and GF were employees of Halozyme Therapeutics, Inc. at the time this trial was conducted. GF is a shareholder of stock at Halozyme Therapeutics, Inc. DCM, PJ, and HMS were employees of Halozyme Therapeutics, Inc. at the time this manuscript was submitted. RKR reports receiving research funding from Merrimack Pharmaceuticals. The other authors declare no conflict of interest.

\section{AUTHOR CONTRIBUTIONS}

Conception and design: JRI, RLK, LSR, JZ, HMS, GF, DDVH, RKR. Development of methodology: SSD, PJ, HMS, GF. Clinical protocols/amendments: JRI, PLR, SSD, JZ, GF, RKR. Acquisition of data (acquired and managed patients, provided facilities, designed the clinical database, case report forms, clinical data collection and cleaning, etc.): JRI, RLK, LSR, PLR, JZ, DDVH, MJB, RKR. Analysis and interpretation of data (e.g., statistical analysis, biostatistics, computational analysis): RLK, SSD, JZ, DCM, GF, PJ, MJB. Writing, review, and/or revision of the manuscript: All authors. Administrative, technical, or material support (i.e., reporting or organising data, constructing databases): JZ, DCM, PJ. Study supervision: JZ, SSD, RKR.

\section{REFERENCES}

Abbott D, Comby P, Charuel C, Graepel P, Hanton G, Leblanc B, Lodola A, Longeart, Paulus L, Peters G, Stadler J (2004) Preclinical safety profile of sildenafil. Int J Impot Res 16: 498-504.

Abetamann V, Kern HF, Elsasser HP (1996) Differential expression of the hyaluronan receptors CD44 and RHAMM in human pancreatic cancer cells. Clin Cancer Res 2(9): 1607-1618.

Allen-Auerbach M, Weber WA (2009) Measuring response with FDG-PET: methodological aspects. Oncologist 14(4): 369-377.

Auvinen P, Tammi R, Parkkinen J, Tammi M, Agren U, Johansson R, Hirvikoski P, Eskelinen M, Kosma VM (2000) Hyaluronan in peritumoral stroma and malignant cells associates with breast cancer spreading and predicts survival. Am J Pathol 156(2): 529-536.

Baumgartner G, Gomar-Hoss C, Sakr L, Ulsperger E, Wogritsch C (1998) The impact of extracellular matrix on the chemoresistance of solid tumors-experimental and clinical results of hyaluronidase as additive to cytostatic chemotherapy. Cancer Lett 131(1): 85-99.

Bertrand P, Girard N, Delpech B, Duval C, d'Anjou J, Dauce JP (1992) Hyaluronan (hyaluronic acid) and hyaluronectin in the extracellular matrix of human breast carcinomas: comparison between invasive and non-invasive areas. Int J Cancer 52(1): 1-6.

Dong Y, Arif A, Olsson M, Cali V, Hardman B, Dosanjh M, Lauer M, Midura RJ, Hascall VC, Brown KL, Johnson P (2016) Endotoxin free hyaluronan and hyaluronan fragments do not stimulate TNF- $\alpha$, interleukin-12 or upregulate co-stimulatory molecules in dendritic cells or macrophages. Sci Rep 6: 36928.
Fraser JR, Laurent TC, Laurent UB (1997) Hyaluronan: its nature, distribution, functions and turnover. J Intern Med 242(1): 27-33.

Frost GI, Stern R (1997) A microtiter-based assay for hyaluronidase activity not requiring specialized reagents. Anal Biochem 251(2): 263-269.

Hayes TJ, Roberts GK, Halliwell WH (1989) An idiopathic febrile necrotizing arteritis syndrome in the dog: beagle pain syndrome. Toxicol Pathol 17(1 Pt 2): 129-137.

Hingorani SR, Harris WP, Beck JT, Berdov BA, Wagner SA, Pshevlotsky EM, Tjulandin SA, Gladkov OA, Holcombe RF, Korn R, Raghunand N, Dychter S, Jiang P, Shepard HM, Devoe CE (2016) Phase Ib study of PEGylated recombinant human hyaluronidase and gemcitabine in patients with advanced pancreatic cancer. Clin Cancer Res 22(12): 2848-2854.

Jacobetz MA, Chan DS, Neesse A, Bapiro TE, Cook N, Frese KK, Feig C, Nakagawa T, Caldwell ME, Zecchini HI, Lolkema MP, Jiang P, Kultti A, Thompson CB, Maneval DC, Jodrell DI, Frost GI, Shepard HM, Skepper JN, Tuveson DA (2013) Hyaluronan impairs vascular function and drug delivery in a mouse model of pancreatic cancer. Gut 62(1): $112-120$.

Jiang P, Li X, Thompson CB, Huang Z, Araiza F, Osgood R, Wei G, Feldmann M, Frost GI, Shepard HM (2012) Effective targeting of the tumor microenvironment for cancer therapy. Anticancer Res 32(4): $1203-1212$.

Knudson CB, Toole BP (1998) Epithelial-mesenchymal interaction in the regulation of hyaluronate production during limb development. Biochem Int 17(4): 735-745.

Kultti A, Zhao C, Singha NC, Zimmerman S, Osgood RJ, Symons R, Jiang P, Li X, Thompson CB, Infante JR, Jacobetz MA, Tuveson DA, Frost GI, Shepard HM, Huang Z (2014) Accumulation of extracellular hyaluronan by hyaluronan synthase 3 promotes tumor growth and modulates the pancreatic cancer microenvironment. Biomed Res Int 2014(2014): 817613.

Lyman GH, Eckert L, Wang Y, Wang H, Cohen A (2013) Venous thromboembolism risk in patients with cancer receiving chemotherapy: a real-world analysis. Oncologist 18(12): 1321-1329.

Maraveyas A, Waters J, Roy R, Fyfe D, Propper D, Lofts F, Sgouros J, Gardiner E, Wedgwood K, Ettelaie C, Bozas G (2012) Gemcitabine versus gemcitabine plus dalteparin thromboprophylaxis in pancreatic cancer. Eur J Cancer 48(9): 1283-1292.

McKee CM, Penno MB, Cowman M, Burdick MD, Strieter RM, Bao C, Noble PW (1996) Hyaluronan (HA) fragments induce chemokine gene expression in alveolar macrophages. The role of HA size and CD44. J Clin Invest 98(10): 2403-2413.

Pilarski LM, Masellis-Smith A, Belch AR, Yang B, Savani RC, Turley EA (1994) RHAMM, a receptor for hyaluronan-mediated motility, on normal human lymphocytes, thymocytes and malignant B cells: a mediator in B cell malignancy? Leuk Lymphoma 14(5-6): 363-374.

Pillwein K, Fuiko R, Slavc I, Czech T, Hawliczek G, Bernhardt G, Nirnberger G, Köller U (1998) Hyaluronidase additional to standard chemotherapy improves outcome for children with malignant brain tumors. Cancer Lett 131(1): 101-108.

Printz MA, Babson B, Selvam P, Beyerlein D, Jiang P, Maneval DC, Sugarman BJ (2017) A Quantitative Method for Determining Hyaluronan Content in Plasma by LC/MS/MS and Plasma HA as a Pharmacodynamic Marker for PEGylated-Hyaluronidase PH20 (PEGPH20) in a Phase 1b Trial for Pancreatic Ductal Adenocarcinoma [poster]. Exhibited at the American Association of Pharmaceutical Sciences National Biotechnology Conference, 1-3 May 2017; San Diego, CA, USA.

Provenzano PP, Cuevas C, Chang AE, Goel VK, Von Hoff DD, Hingorani SR (2012) Enzymatic targeting of the stroma ablates physical barriers to treatment of pancreatic ductal adenocarcinoma. Cancer Cell 21(3): 418-429.

Rilla K, Pasonen-Seppanen S, Karna R, Karjalainen HM, Torronen K, Koistinen V, Tammi MI, Tammi RH, Teräväinen T, Manninen A (2012) HAS3-induced accumulation of hyaluronan in 3D MDCK cultures results in mitotic spindle misorientation and disturbed organization of epithelium. Histochem Cell Biol 137(2): 153-164.

Ropponen K, Tammi M, Parkkinen J, Eskelinen M, Tammi R, Lipponen P, Agren U, Alhava E, Kosma VM (1998) Tumor cell-associated hyaluronan as an unfavorable prognostic factor in colorectal cancer. Cancer Res 58(2): 342-347.

Setala LP, Tammi MI, Tammi RH, Eskelinen MJ, Lipponen PK, Agren UM, Parkkinen J, Alhava EM, Kosma VM (1999) Hyaluronan expression in gastric cancer cells is associated with local and nodal spread and reduced survival rate. Br J Cancer 79(7-8): 1133-1138. 
Shepard HM (2015) Breaching the castle walls: hyaluronan depletion as a therapeutic approach to cancer therapy. Front Oncol 5: 192.

Shepard HM, Frost GI, Rybak ME, Ramanathan RK, Von Hoff DD, Infante JR, Rosen S, Leff J (2010) Targeting Hyaluronan (HA) in the Tumor Stroma: Translational Evaluation of Pegylated Hyaluronidase (PEGPH20) in Animal Models and Patients with Advanced Solid Tumors [poster]. Exhibited at the 4th ASCO-NCI-EORTC Annual Meeting on Molecular Markers in Cancer; 18-20 October 2010; Hollywood, FL, USA.

Therasse P, Arbuck SG, Eisenhauer EA, Wanders J, Kaplan RS, Rubinstein L, Verweij J, Van Glabbeke M, van Oosterom AT, Christian MC, Gwyther SG (2000) New guidelines to evaluate the response to treatment in solid tumors. European Organization for Research and Treatment of Cancer, National Cancer Institute of the United States, National Cancer Institute of Canada. J Natl Cancer Inst 92(3): 205-216.

Thompson CB, Shepard HM, O'Connor PM, Kadhim S, Jiang P, Osgood RJ, Bookbinder LH, Li X, Sugarman BJ, Connor RJ, Nadjsombati S, Frost GI (2010) Enzymatic depletion of tumor hyaluronan induces antitumor responses in preclinical animal models. Mol Cancer Ther 9(11): 3052-3064.

Toole BP, Slomiany MG (2008) Hyaluronan: a constitutive regulator of chemoresistance and malignancy in cancer cells. Semin Cancer Biol 18(4): 244-250.

US Department of Health and Human Services (2009) Common Terminology Criteria for Adverse Events (CTCAE) Version 4.0. US Department of
Health and Human Services: Washington, DC, USA; NIH Publication No. 09-5410.

Veneziale RW, Printz MA, Sugarman BJ, Lalayeva N, Ruppert GW, Polhamus K, Maneval DC, Lapinskas PJ (2015) Toxicity and Toxicokinetics of PEGPH20 in the Monkey and Rat [poster]. Exhibited at the 54th annual meeting of the Society for Toxicology; 13-17 March 2015; New Orleans, LA, USA.

Whatcott CJ, Diep CH, Jiang P, Watanabe A, LoBello J, Sima C, Hostetter G, Shepard HM, Von Hoff DD, Han H (2015) Desmoplasia in primary tumors and metastatic lesions of pancreatic cancer. Clin Cancer Res 21(15): 3561-3568.

Zoltan-Jones A, Huang L, Ghatak S, Toole BP (2003) Elevated hyaluronan production induces mesenchymal and transformed properties in epithelial cells. J Biol Chem 278(46): 45801-45810.

(c) (1)(2) This work is licensed under the Creative Commons cc. national License. To view a copy of this license, visit http:// creativecommons.org/licenses/by-nc-sa/4.0/

(C) The Author(s) named above 2018

Supplementary Information accompanies this paper on British Journal of Cancer website (http://www.nature.com/bjc) 